\title{
DRAMATURGIA COSTARRICENSE
}

\author{
POR \\ VIRGINIA SANDOVAL DE FONSECA \\ Universidad de Costa Rica
}

Nuestra literatura comenzó a gestarse en el siglo xIX, aunque sólo a partir de las primeras décadas del xx definió sus principales directrices.

E1 desenvolvimiento del teatro se suele dividir en tres etapas: a) los comienzos; $b$ ) período de transición, y c) teatro consolidado.

\section{PrIMERA ETAPA: LOS COMIENZOS}

Se extienden hasta los dos primeros decenios del siglo xx. Apenas hay alguna noticia poco trascendente de la época colonial. Ya es un lugar común aludir a la pobreza y aislamiento de Costa Rica en ese entonces, poco propicio para el desarrollo del teatro.

En términos generales, los autores de los comienzos nacieron en la segunda mitad del siglo XIX y produjeron sus obras en las dos primeras décadas del xx. Se exceptúan José Joaquín Oreamuno y Víctor de la Guardia, cuyas obras se ubican en las postrimerías del xix; también Rafael Carranza, el primero que revela acierto en el uso de los resortes dramáticos con Un duelo a la moda (1885). Otra excepción corresponde a José Fabio Garnier, puente de paso para entrar en el período de transición.

Otros nombres que caben aquí son: Emilio Pacheco Cooper, Joaquín Barrionuevo, Ernesto Martén, Manuel Escalante y Gonzalo Sánchez.

Entrada ya la centuria siguiente, se asoman especialmente las obras de Carlos Gagini (1865-1925), Ricardo Fernández Guardia (1867-1950), Daniel Ureña (1876-1933), Eduardo Calsamiglia (1880-1918) y José Fabio Garnier (1884-1956).

E1 maestro y lingüista Carlos Gagini se inició teatralmente en 1905 con Los pretendientes, la zarzuela El marqués de Talamanca y el juguete 
cómico Don Concepción. Este último es texto de estudio en los programas nacionales de literatura. En un acto, trata de las incidencias que vive una familia campesina que se traslada a la ciudad. El proyecto de incorporación al nuevo medio toma en escena tres direcciones, frustradas todas: a) la social, cuya meta visible radica en la aspiración de la familia a ser invitada al baile de la Independencia; $b$ ) la política, expresa en el deseo de don Concepción de convertirse en candidato, y c) la económica, por la cual el protagonista aspira a ser accionista de la United Co. Pacaca Puriscal.

Varios fuera de escena refuerzan el desgarre del campesino en la ciudad: las compras de objetos cuyos nombres y usos desconoce; la creencia, errónea, de que el ministro don Eugenio es amigo personal de don Concepción; las relaciones con las Vicentinas para obras de caridad, y las alusiones al baile, al que sólo será invitada Helósa.

Tres grandes sujetos actúan en la cadena de frustraciones: en el plano social, el sujeto la familia anhela incorporarse al medio urbano (busca aceptación social). Se opone a ello su estado de ignorancia; carece de apoyo para sus propósitos, pues la supuesta mediación de don Eugenio no llega. En el plano político, el sujeto Don Concepción quiere ser candidato ja diputado o presidente, qué más da! Se opone a tal ansia su condición de ignorante. Tampoco tiene ayudantes verdaderos, pues Venancio, propiciador del bien apetecido, sólo quiere explotarlo; lo exhibe como "candidote» y no como candidato; además, lo utiliza para atacar al gobierno. Lo único que alcanza el pobre aspirante a político es su confinamiento por orden ministerial. En el plano económico, el sujeto Caralampio desea estafar a don Concepción con la venta de acciones de una fingida compañía minera. Ayudan a la consumación del hecho la ignorancia del comprador y las persuasivas palabras de Venancio. No hay quien se oponga a las intenciones de Caralampio Lagartijo. La astucia malintencionada de estos compadritos urbanos propicia el éxito de la estafa, que favorece a Caralampio.

¡Cómo evoluciona don Concepción! Al principio creía que el estudio era superfluo, sobre todo para las mujeres: «... las mujeres no necesitan ciencia, sino saber remendar los calzones del marido, freírle los frijoles y echarle de cuando en cuando una tortilla rellenas ${ }^{1}$. Pero después de la dolorosa experiencia en la ciudad, se convence de su error.

De ese modo se conforma el punto de vista de su sobrina Heloísa, cuyo pensamiento encarna la tesis de la obra: la base del éxito en la vida depende de la educación.

\footnotetext{
${ }^{1}$ Carlos Gagini, Teatro (San José: Editorial Costa Rica, 1963), pp. 205-206.
} 
Mediante la sátira se ridiculizan: a) la ignorancia, no el campesino (Heloísa, triunfadora, también era campesina, pero había estudiado); b) las penurias económicas de los maestros mal pagados; c) la maldad urbana. Era tópico realista ubicar la procedencia del mal en la ciudad. Los malos de la pieza son Venancio Sordina y Caralampio Lagartijo, y, en alguna medida, don Eugenio; d) los vicios políticos, que han conducido a una crisis de valores; e) el orgullo o menosprecio de los que, habiendo llegado a posiciones altas, olvidan su origen humilde y a sus iguales de otrora, como ocurre con don Eugenio, y f) el mal servicio eléctrico, a cargo de la compañía tranviaria.

Por otra parte, alude a la vocación democrática de los costarricenses. Cualquier ciudadano podía aspirar a las máximas magistraturas, así fuera «milpero» o «frijolero».

Evidencia también el desarrollo del periodismo: la famosa gaceta en que apareció el «candidote» convulsionó al gobierno.

En 1902, cuando se estrenó Don Concepción, su autor se hallaba en plena madurez: tenía treinta y siete años. A él y a los espectadores les correspondió vivir el cambio rotundo que va de la Costa Rica gobernada por las oligarquías al Estado de pensamiento liberal. Esta última orientación no estuvo exenta de realizar persecuciones contra el bando opuesto (confinamiento de don Concepción). Sin embargo, mostró verdadero interés por la tarea educativa. La tesis sobre la importancia de ésta corresponde al trasfondo histórico, cuyas raíces se hunden en la reforma de don Mauro Fernández.

La escenificación está prevista con economía espacial: nada más que una sala lujosa. A ello se añade el lenguaje vernáculo en prosa; lo cómico de situación, que apunta en la divergencia entre el esfuerzo de la familia emigrante por lograr sus objetivos y los frustrantes resultados; lo cómico verbal, visible en los detalles; los nombres propios escogidos y deformaciones de los términos a causa del desconocimiento del nombre y uso de los objetos. Don Concepción forma parte de las obras clásicas nacionales. Otras piezas de Gagini son: El candidato, Las cuatro y tres cuartos, El reino de Flora, Trocitos de carbón, etc.

Eduardo Calsamiblia es conocido por su obra El combate y otras obras dramáticas, publicada por la Imprenta Moderna en 1914. Sobresale la pieza que le da el nombre al volumen, El combate, pero cabe añadir Poderes invisibles, iEl!, Ni el cielo, etc.

El combate (tres actos en prosa) presenta dos grandes núcleos de acción: a) el adulterio de Lucía, y b) la tarea científica de Arturo. El primero es movido por el eje del deseo, que crea la esfera de la pasión. Lucía, ávida de goces mundanos, traiciona a su marido. El segundo núcleo 
trae al doctor Arturo Mariscal, dedicado a la investigación científica. Descubre el antídoto contra la tuberculosis, sobre todo para curar a su $\mathrm{mu}-$ jer. Aquí el eje es la razón, fundadora de la esfera del saber, que, en última instancia, se resuelve en poder. El espacio creado por la actuación del hombre de ciencia será el dominante.

La tradición dramática imponía el sistema honra-deshonra-venganza (fórmula calderoniana). Arturo, después de horas de crisis, adopta la fórmula honra-deshonra-no venganza. Para 1legar a esa meta libra un doble combate (de allí procede el nombre de la pieza), en cada una de cuyas fases debe sacrificar algo. En el combate contra la enfermedad, como científico, sacrifica su amor: debe hurtarle tiempo a éste para encontrar el remedio contra la tuberculosis. En el combate contra los impulsos pasionales, como hombre herido en su honra, sacrifica la venganza.

En los primeros decenios del siglo xx gravita la herencia de la Ilustración, adobada con el influjo del positivismo, suficientemente visibles en esta pieza. También cuentan los progresos habidos en la medicina hasta esa época. En síntesis, la relación agónica hombre versus médico equivale a pasión e instinto versus razón y ciencia.

Daniel Ureña ha sido postergado por el olvido. Sin embargo, se dedicó por entero al teatro. De sus obras se conservan María del Rosario (1906) y Los huérfanos (1910), inclinadas hacia la denuncia contra la violación de las buenas costumbres. Sabe complicar la intriga y crear suspense.

Ricardo Fernández Guardia fue esencialmente historiador; escribió, además, muy buenos cuentos y crónicas y sólo una obra de teatro, Magdalena (1902), traída recientemente a escena (1984) por la Compañía Nacional de Teatro. A pesar de su punto de vista cosmopolita en torno a los temas literarios, en el prólogo de Magdalena declara su intención de contribuir a que se cree el teatro de carácter nacional.

Don Concepción alude a criaturas pertenecientes al capitalismo agrario; Magdalena, a los miembros de la recién enriquecida oligarquía cafetalera, en la cual se despierta la avidez por el lujo y los refinamientos europeos. Presenta una intriga amorosa — con varias ramificaciones-, sostenida por un sustrato ideológico, que intenta romper los patrones tradicionales, según los cuales la mujer ha de estar sometida al dominio del varón. Magdalena se debate entre el amor de dos hombres: Rafael, un buen partido, representante de la tradición, ve en la mujer a una criatura indefensa, dependiente para todo del sexo fuerte; Fernando, primo de la protagonista, recién llegado de París, inclinado al goce de la vida y a la liberalización de las costumbres. Pero cuando decide casarse escoge a María (hermana de Magdalena), que se mantiene dentro del marco de la 
mujer sumisa. ¿Embrión feminista? Por lo menos, Magdalena enjuicia críticamente los convencionalismos de la sociedad a que pertenece. Se impone finalmente el espíritu conservador. El eje de la acción se articula como voluntad personal versus presión social. Esta es muy fuerte. Fracasa el proyecto de Magdalena.

José Fabio Garnier cierra el teatro de ese período, aunque su acción se extiende hasta mediados de esta centuria. Sus temas ya no tienen matices locales; su ámbito es cosmopolita. Prefiere la pugna de las pasiones humanas. Su obra no está exenta de crítica, descarnada a veces, quizá a causa del escepticismo del autor ante la vida. Maneja con precisión los recursos técnicos de la escena, lo mismo que elementos melodramáticos propios de la alta comedia. Precursor del nuevo período, escribió alrededor de cuarenta piezas, algunas de las cuales son: Nada y El retorno (1912), Segundo coloquio de los perros y Bocaccesca (1918), A la sombra del amor (1921), El talismán de Afrodita (1929), Si el marido engaña (1954), Si el diablo sopla y La doncella que quiso volver (1955).

\section{SEgUNDA ETAPA: PERIOdO DE TRANSICION}

Esta etapa está formada por autores cuya creación se ubica en las décadas tercera y cuarta de nuestro siglo. Allí se inscriben Alfredo Castro (1889-1966), los productores de teatro infantil, como el gran lírico Carlos Luis Sáenz (1899-1983), María del Rosario Ulloa de Fernández, Aída Fernández de Montagné, Lilia Ramos, Albertina Fletis de Ramírez, etc. También pertenecen a esta etapa Alfredo Saborío, Raúl Salzar Alvarez, Abel Robles Chacón, Gonzalo Chacón Trejos, Manuel Escalante, Ricardo Jiménez Alpízar, Carlos Orozco Castro, Manuel Segura Méndez, algunos de ellos sólo con una obra y otros con más, así como José Basileo Acuña (1897).

H. Alfredo Castro, costarricense de nacimiento, desde muy niño se educó en Francia, por lo cual escribió en francés. Experimentó la influencia de las escuelas vanguardistas, sobre todo del surrealismo. Lleva a escena crisis psicológicas e ideológicas. En ocasiones censura los convencionalismos sociales con humor negro.

Aguas negras, en tres actos, ha sido su obra más difundida. Se conoció en Costa Rica, en 1947, por la traducción de los profesores universitarios María Rosa Picado y Abelardo Bonilla. Es compleja y quizá difícil para el montaje. Posee un contenido riquísimo. La misma expresión aguas negras es plurisignificativa: expresa un nombre geográfico, una región inhóspita, una fiebre maligna, las malas pasiones y la fuerza avasalladora de la zona y de los instintos. 
Se desliza en dos planos, enfundados en recursos surrealistas: el humano y el de la naturaleza. En el primero de ellos surgen las relaciones conflictivas entre Miguel y Raúl, dos hermanos que apetecen la misma mujer: Vera. Generan un caso de cainismo; pero Miguel, el marido, no es pasivo como el Abel bíblico, sino que urde su venganza: al tomar el té con chigua (veneno), se librará de ser víctima de la zona y separará para siempre a los amantes. La crisis salta del complejo de culpa al de castración, con el distanciamiento definitivo de la pareja traidora. El diálogo con Adoración funciona como vehículo que transporta a la superficie lo que ocurre en el subconsciente de Vera.

En el plano de la naturaleza se enfrentan dos personajes portadores de concepciones de vida opuestas y de mitos antagónicos: Buxter, empresario bananero, cuya tecnología es la única capaz de dominar aquella zona del trópico, pantanosa y hostil, presumiblemente del Atlántico, quizá de Costa Rica, y el Cristo Negro, en realidad el doctor Tilbury. Este admira, primero, el progreso; pero lo repudia cuando constata la deshumanización que implica. Se convierte entonces en el Cristo Negro (con su particular pasión) y funda el mito del Espíritu de la Zona para rescatar el respeto por el ser humano. Buxter crea el mito del Hombre de 1a Tierra, utilitarista y degradante. No obstante, ambos mitos se aniquilan recíprocamente. El Hombre de la Tierra acaba realizando verdaderos genocidios, ya no para contrarrestar ritos bárbaros, sino por el gusto de matar; el Espíritu de la Zona, al comienzo altruista, deja salida al odio atávico del negro contra el blanco.

Otro conflicto que emerge en el plano de la naturaleza se produce entre nativos y foráneos. Estos, procedentes del mundo civilizado, sujetos a sus convencionalismos y principios éticos y sociales, sucumben ante el poder devorador de la zona: mueren, como Miguel, o se van enfermos a terminar sus pocos días a otra parte, o se degradan moralmente, como Vera, Arturo y los trabajadores de Buxter. Al final, cuando han desaparecido todos los extraños, Adoración es la dueña de la zona. Hasta el bungalow, que había sido la vivienda de Vera, es invadido por la vegetación, símbolo del dominio de aquella naturaleza aniquilante de Aguas Negras.

Otras piezas de Castro Fernández, cuyo seudónimo fue Marizancene, son: El punto muerto, El vitral, Fragata bar, La horma de su zapato, El amero, Pounette, Esta noche, esta noche, Juego limpio, La rama de Salzburgo, Espiritu de rebeldía.

José Basileo Acuña, premio Magón 1983, es poeta, dramaturgo y narrador; ha realizado excelentes traducciones de Shakespeare (Sonetos, Comedia de las equivocaciones, Hamlet). Entre las obras teatrales de su 
invención cuenta Intiada, Poema sagrado del sol. Le valió el premio Nacional de Teatro «Aquileo J. Echeverría» en 1970. Consta de 3.353 versos, distribuidos en tres actos; su composición oscila entre 1947 y 1962, aunque se publicó mucho después. Escenifica el surgimiento del Imperio incaico, desde los sobrevivientes de la legendaria Atlántida hasta la aparición de los incas y el Cuzco con Manco Cápac y mama Ocllo. Está impregnada de filosofía oriental y de saber mítico, histórico y teosófico.

Su otra obra, de visible originalidad, es Máscaras y candilejas (1972). Inciuye diez piezas en un acto y una con tres. Fueron escritas entre 1965 y 1971. Son farsas de sátira desgarrada, que critican vicios sociales, políticos y económicos, el asentamiento de las oligarquías, convencionalismos, falsos mitos y el estrujamiento de lo humano en pro del avance tecnológico. Sobresale Chica-Pica, en la que coinciden personajes históricos. (Diógenes, Alcibíades, Sócrates), literarios (Edipo), con otros comunes (el campesino Aquiles, el beodo, el niño). Administra muy bien el lenguaje preciosista de las figuras nobles y el estilo jergal de los comunes. También vale la pena nombrar Tiquismiquis, Venta de cachivaches, Dante Alighieri. Máscaras y candilejas, aunque no evade totalmente la propensión narrativa, revela un gran dominio del lenguaje, tanto culto como. popular, tanto en prosa como en verso. Defiende siempre el sentido espiritualista de la vida.

\section{TERCERA ETAPA: TEATRO CONSOLIDADO}

Domina este período la trinidad dramática formada por Alberto Cañas (1920), Samuel Rovinski (1932) y Daniel Gallegos (1930), los que más han producido. Por supuesto que hay otros autores que también han contribuido a consolidar el teatro de hoy: Alfredo Sancho, cuya labor inicial la realizó en Costa Rica, pero después se domicilió en Míxico; Víctor Manuel Arroyo, Antonio Yglesias, que se ha convertido en cineasta; Olga Marta Barrantes, Eugenia Chaverri, Manuel Angulo, William Reuben, William Zúñiga, Alejandro Herrera, Lupe Pérez Rey, Carmen Naranjo, Joaquín Gutiérrez, Juan Fernando Cerdas, Víctor Valdelomar, Manuel Rojas, etc.

Samuel Rovinski, ingeniero de profesión, hombre muy culto, ha escrito narrativa y teatro. Este ha tomado dos direcciones: la farsa y el drama serio. Merecen destacarse:

Gobierno de alcoba (1961), en un acto, estrenada en 1967, es una denuncia política aplicable a la situación de más de una localidad latinoamericana en que los golpes de Estado o las revoluciones no resuelven 
los problemas, pues sólo ocurre que el poder cambia de manos. Tal sucede en el paso del tiranuelo don Leoncio al revolucionario Martínez. María, la amante de aquél, encarna al pueblo. Cuando llega el nuevo amante de turno, Martínez, éste tampoco toma en cuenta las ansias de la mujer-pueblo, pues comete las mismas aberraciones políticas.

De Las fisgonas de Paso Ancho (1971), en un acto, se dijo que era «teatro para barrios». Hoy debiera rectificarse y afirmar que es «teatro acerca de barrios», porque ese tema popular, tratado mediante la farsa, gusta a todos los públicos. Las vecinas de Hernán oyen que éste disputa con su madre y con su esposa por cuanto no es atendido inmediatamente. Ellas no quieren perder un solo episodio de la telenovela. Las vecinas, ante la gresca, atribuyen al hombre una serie de delitos contra las dos parientes y... llaman a las autoridades: guardia civil, radiopatrulla y bomberos. Pero no había tal incendio, ni afición a las drogas, ni intento de asesinato, a pesar de que un radioperiódico contribuyó a que el pleito familiar degenerase en grotesco espectáculo. Esta pieza se convierte en una sátira contra las telenovelas; contra el hiperbólico daño ocasionado por la morbosa intervención del vecindario en la vida ajena, y, sobre todo, contra la prensa sensacionalista, que adultera los hechos con ingredientes de pésima calidad.

Un modelo para Rosaura (1975), en tres actos, ganó el premio Editorial Costa Rica y luego el premio Nacional de Teatro «Aquileo J. Echeverría». Cada obra de Rovinski representa un esfuerzo más para llevar a la práctica avanzadas técnicas teatrales. Ejemplo de tal propósito es $E l$ martirio del pastor (1984). Se basa en el asesinato de monseñor Romero, ocurrido en El Salvador. Su línea de acción predominante es históricopolítica: comprende las relaciones Estado-Iglesia-pueblo. Hay otra, la psicológica, representada por la amistad de monseñor Romero con el padre Grande.

La primera tiene dos fases, correspondientes a la evolución del protagonista y a dos momentos de la relación Iglesia-Estado. En el primero, Monseñor tiene una actitud reservada en cuanto a lo político, pues no quiere que la Iglesia intervenga en ese campo. Pretende que, mediante la prédica evangelizadora, los malos ciudadanos (ricos, militares y poderosos) reconozcan que se hallan en pecado y rectifiquen su conducta para salvación de sus almas y beneficio del pueblo. A raíz de la muerte del padre Grande, el prelado adopta una actitud beligerante (segundo momento) contra la oligarquía y los militares, causantes de la pérdida de su amigo. Por fin, el ex mayor Farfán, asesino pagado, mata al arzobispo en pleno oficio religioso, según designio oligárquico-militar. La línea psicológica es débil, pero permite advertir que si hubo cambio político en mon- 
señor Romero fue como tributo a la amistad con el padre Grande. E1 acontecer no ahonda en lo que ocurre en el espíritu del protagonista; sólo se interesa por la cara externa de los hechos. Ambas líneas de acción se deslizan entre golpes de Estado, rebeliones, persecución, duelos, sangre y noticias tergiversadas por la prensa al servicio del poder público.

Para la puesta en escena, siempre dentro de ese esfuerzo permanente de experimentación, Rovinski emplea recursos técnicos avanzados: luces con los más variados enfoques y ubicaciones (no sólo en el escenario); proyecciones en pantallas que aspiran a integrarse a la acción unas veces, a servir de comentario otras, y en ocasiones, a cumplir un papel indicador (especie de subrayado); los magnavoces colaboran con los mismos propósitos; otro tanto puede decirse del decorado, apto para coincidir con las variadas localizaciones de la acción. Se trata de un ejercicio de técnica brechtiana. La última obra conocida de Rovinski es La víspera del sábado. En términos generales, parece que este autor se mueve con más holgura en la comedia que en la tragedia.

Daniel Gallegos, abogado de profesión y hombre de teatro por especialización y preferencia estética, profesor universitario, conoce el teatro por dentro, pues además de dramaturgo ha sido actor, director y escenógrafo. Laureado varias veces con premios nacionales e internacionales, puede afirmarse que el suyo es un teatro de ideas. Pero no se vaya a creer que este calificativo sobrepone el logos al pathos, sino que éste se nutre de aquél.

Sus piezas teatrales tienen en común el análisis de la condición humana; la frectuente alusión a choques generacionales que exhiben convencionalismos y falsos valores de una sociedad en crisis; la ansiedad por restaurar el equilibrio, aunque sus criaturas se equivoquen a veces en esa busca. Las tres mejores obras de Gallegos son: La colina, Punto de referencia y En el séptimo círculo. Otras son: Ese algo de Dávalos, Los profanos, La casa, etc.

La colina (tres jornadas) fue estrenada en 1968 y publicada el año siguiente. Premio Nacional de Teatro «Aquileo J. Echeverría» de 1968, suscitó una gran polémica. Comienza con la noticia de la muerte de Dios, difundida por las Naciones Unidas. Este punto de partida y el hecho de añadir que es un «auto sacramental» confundió a los incautos, que la tomaron por una obra irreverente contra la religión. Pero nada más lejos de esa actusación: se trata de una obra cuyos planteamientos filosóficos presentan un mundo dislocado por la falta de Dios, como varias veces se palpa en los tiempos que corren. El universo de La colina deja sin fundamento todo lo que en Dios tiene su base; ya no hay razón para el pecado ni para la culpa. ¿La supresión de este primer motor - como diría 
el filósofo-, no funda acaso un mundo absurdo? Por esa vía, en una especie de psicodrama, los personajes desnudan sus conciencias ante ellos mismos y ante los espectadores, con un juego-juicio que explica sus respectivas conductas. Descubren entonces que, aunque Dios haya muerto, siguen existiendo el infierno en cada sujeto, producto de sus terrores y angustias. Aceptada la muerte de Dios (sin examen alguno, como antes su existencia), se producirá el descenso de la colina, de modo diferente para cada personaje. Gráficamente se puede representar así:

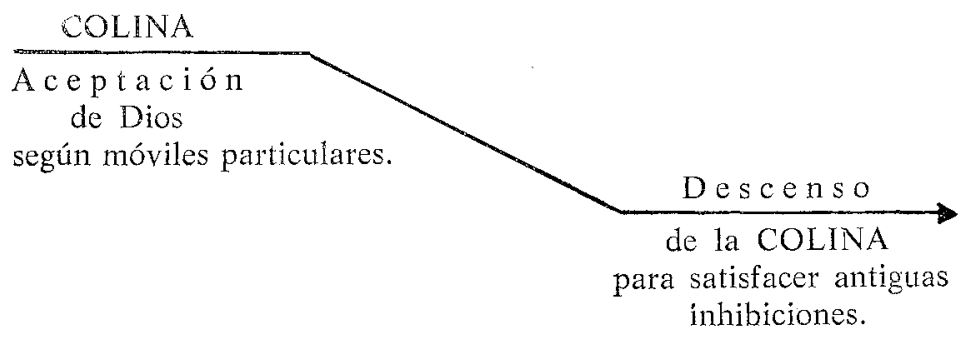

En el fondo prevalece una actitud deísta. Descubren que Dios nace y muere en cada uno de nosotros y que lo podemos encontrar en el amor a los demás. Cuando cae el telón, aparte de la confesión religiosa que cada uno siga, el hombre podrá observar que no puede vivir sin absolutos e indagará su relación con la idea trascendente de Dios.

Punto de referencia (dos actos) fue estrenada en la Sala Vargas Calvo del Teatro Nacional en 1984. Bucea en el subconsciente de sus criaturas, para plantear los problemas de la identidad y de las relaciones interpersonales de la pareja. Estas van desde la amistad hasta el amor. Así, de las esquinas sombreadas de la infraconsciencia van emergiendo los monstruos espirituales.

¿Por qué se llama Punto de referencia esta obra, considerada por la crítica como una de las mejores de los últimos años? «Para justificar o explicar la conducta de los caracteres - dice el crítico Guido Fernández-, Daniel Gallegos desarrolla la obra en planos atemporales y reminiscentes. Ahí se cuenta, entonces, la historia de los primeros encuentros, donde salen a la superficie las extrañas, inconclusas, excepcionales maneras de relacionarse Jorge y Esteban, y de ambos con Ana, los primeros unas veces como padre e hijo, otras como amigos, otras como amantes. Ana es, en esa instancia, la intrusa desconfirmada, plenamente presente unas veces, otras apenas asomada a un mundo ininteligible, para ella misterioso.»

El autor rinde tributo, con esta obra, a las grandes figuras del teatro 
universal, muy especialmente a Strindberg. Se vale de Esteban —quien a veces parece real y otras engendro de las mentes de Ana y Jorge- para analizar también la relación de éstos, desde quince años atrás. El otro, real o supuesto, gravita entre los cónyuges. Ambos se hallan condicionados por sus obsesiones. Sólo queda el mecanismo del olvido para apaciguar sus almas atormentadas, a sabiendas de que ello sólo será posible en la medida en que las memorias punzantes se atenúen hasta convertirse en punto de referencia.

En el sépitimo círculo (1982), en dos actos. El séptimo círculo del infierno dantesco estaba destinado para los violentos, sodomitas, criminales, etc. En la obra de Gallegos está constituido por una casa-fortaleza, cuyas compuertas electrónicas se cerrarán para enclaustrar allí a dos generaciones antagónicas: la vieja y la joven. El acontecer, organizado cíclicamente, apunta a varios momentos dramáticos sucesivos, reiteradores de la violencia: a) El temor de los viejos, por lo cual toman medidas de seguridad que impidan el ingreso de extraños; b) La violencia de los jóvenes, que reclama a los viejos su cómoda e indiferente posición ante el mundo; c) La violencia de los viejos en venganza por el recién pasado atropello, y d) El reinicio de la violencia juvenil.

El eje semántico de esta pieza oscila entre los polos AGRESION/NO AGRESION, bajo la forma de violencia - de palabra, de acción, psicológica y sexual-, cada una de las cuales se imbrica en las demás. Repudia los falsos valores; muestra la pugna generacional y sedimentos de tipo freudiano (la libido, el odio, el parricidio psicológico, el desembozo de tabúes). En efecto, los viejos, conformistas o conservadores, aspiran a la tranquilidad (no violencia), acorde con sus valores e intereses. Desde que los invaden los jóvenes, la acción se convierte en flujo y reflujo de agresores y agredidos, por lo cual el polo dominante será el de la agresión. La casa de Félix y Esperanza comienza como espacio físico (lugar de los hechos); se convierte en casa-fortaleza, por las medidas de seguridad adoptadas por sus dueños; en casa-círculo, por la reiteración de las situaciones (agresores-agredidos) y por su cierre hermético; por último, en casa-infierno, círculo donde se han citado la iracundia, violencia, tiranía y demás aberraciones humanas de estos grupos. Los viejos, atrapados por la sociedad de consumo, son incapaces de comprender el furor juvenil. Se les acusa de ignorar deliberadamente la realidad, de prohijar falsos valores, de situar la meritocracia en la posesión de más y más objetos y de convertir a sus hijos, egoístamente, en herederos de los intereses de sus progenitores.

Pero se trata de una sociedad mutilada: los viejos, porque están ignorantes de las causas del actual estado de cosas; los jóvenes, porque, a 
pesar de su disconformidad, no tienen ninguna solución que ofrecer; sólo son iconoclastas. Tanto padres como hijos pertenecen al mismo estrato burgués, disfrutan de sus conveniencias y cumplen los mismos hábitos. Todos quedan atrapados por un determinismo social, generado por la sociedad de consumo, que aniquila al hombre y lo desplaza de su centro. Así, la máxima rousseauniana del hombre naturalmente bueno se ha convertido en la del hombre primordialmente violento. Gallegos ha escenificado un estado de mundo, sin pretensión de ofrecer soluciones, sino de diagnosis de nuestro tiempo. Por eso sus criaturas saltan de su yo visceral a lo trascendente, para denunciar la orfandad del hombre moderno, fin para el que han colaborado palabras, gestos, decorados y símbolos de esta ingeniosa pieza, que se acerca un tanto al teatro de la crueldad.

Alberto Cañas. Desde finales de la década del cincuenta hasta el presente, este abogado, político y escritor es el dramaturgo que más obras ha incorporado al teatro costarricense, sin contar sus novelas, cuentos, ensayos, artículos periodísticos, crítica y su labor de profesor universitario. Es también el autor que más premios ha obtenido por su labor literaria, entre ellos el Magón, el más alto del país.

Entre sus muchas obras dramáticas sobresalen: El luto robado, La segua (recientemente llevada al cine), Uvieta, y Oldemar y los coroneles. Además de las aludidas: Algo más que dos sus dos sueños. El héroe, Los pocos sabios, En agosto hizo dos años, Operación T. N... T., Tarantela, Ni mi casa es ya mi casa, Una bruja en el río, Eficaz plan para resolver la desnutrición infantil y de paso los problemas fiscales.

El luto robado (1963), pieza en tres actos, fue estrenada en 1962 y publicada el año siguiente, tras obtener el premio Nacional de Teatro «Aquileo J. Echeverría» de 1962. Los tipos con que está construida, inscritos en la vertiente del absurdo, muestran a los espectadores un mundo incomprensible y alógico. Parten de una situación susceptible de ser explicada razonablemente. La muerte de Rosita no aflige a su novio, Germán, por cuanto él no fue el primer hombre en la vida de ella. Pero un antiguo compañero de aquél, el boticario Ponce, casado con la grotesca Ninfa, siempre ha amado en secreto a Rosita. Entonces viene lo absurdo: mediante el recurso que el protagonista llama «eutanasia oblicua», decide proporcionarle un duelo a Ponce, envenenando a Ninfa. Así, cuando el viudo reciba las condolencias por la desaparición de su esposa, podrá aceptarlas como si fueran por la amada platónica y exteriorizar así su dolor.

La pieza ofrece dos líneas de acción: la de los convencionalismos y la de la muerte de las dos mujeres. Los convencionalismos escenifican tres visitas de pésame, exactamente iguales en gestos y palabras, aunque 
varíen los respectivos sujetos. A fuerza de repetirlos, los actos se vuelven mecánicos y van perdiendo significado. Entre visita y visita, Germán cambia sus ropas de luto (otro convencionalismo) por las de fiesta, mientras se entretiene con su amiga Cecilia.

El espacio en que se mueven los personajes queda dividido en dos porciones: la sala de recibo y el bar. El juego de apariciones y desapariciones de personajes, complementado con el paso de luz a sombra o viceversa, puede compararse con la técnica cinematográfica del fundido. En la otra línea de acción, Germán cuenta a Cecilia (función de confidente) la historia de Rosita; pero evade la narratividad, porque actualiza los hechos a modo de flash back. Se sabe entonces que la novia aceptaba, en apariencia, los convencionalismos sociales, pero en lo íntimo los violaba: era su modo de rebeldía.

Otro episodio dependiente de esta misma línea de acción (en que Cecilia desempeña la función de cómplice involuntaria) está constituido por el asesinato contra Ninfa. A pesar de los esfuerzos de Cecilia por evitarlo, la mujer del boticario perece como lo quiso Germán. Este y Cecilia no se pueden entender: ella apela a la lógica; Germán, a premisas absurdas.

Las criaturas de ese mundo, así concebido, quedan condenadas a la incomunicación - aunque hablen- como Ponce y Rosita, Cecilia y Germán, Germán y las visitas; o caen en los actos fallidos, como le ocurre al protagonista al pretender devolverle a Ponce el luto robado. Germán se convierte en un héroe frustrado, reducido a contemplar su fracaso: el boticario sî quería a su mujer y ahora le duele la soledad.

Al teatro del absurdo podría atribuírsele lo mismo que Valle-Inclán pone en boca de uno de sus personajes sobre el «esperpento»: «está más allá del dolor y la risa». En verdad, El luto robado no es cómico, aun cuando satiriza la automatización de los convencionalismos sociales; tampoco trágico, a pesar de las muertes provocadas contra las mujeres y a pesar del dolor de Ponce y de la desaprobación de Cecilia. Al violar la ley de la causalidad con la eutanasia indirecta e imponer los fríos razonamientos de Germán, basados en falsas premisas, sólo queda rigiendo el absurdo. La condición humana apunta, pues, hacia la frustración.

Oldemar y los coroneles, escrita hace varios años, se estrenó y publicó en 1984. Consta de tres actos, distinguidos por denominaciones musicales: acto I (andante), acto II (allegro assai), acto III (allegro), acordes con el ritmo progresivo de la acción.

El conflicto se inicia porque aparece Oldemar Vindas, sobreviviente de la masacre de Santa Eulalia (los militares habían acribillado a una veintena de personas, niños y mujeres). Para que guarde silencio, recibe sucesivas cantidades de dinero y otras prebendas, entre ellas el ascenso 
social. Cuando Oldemar se ha enriquecido, se invierte la situación conflictiva: ahora él es objeto de chantaje por parte de los militares: lo amenazan con atribuirle el referido crimen.

En otras palabras: escenifica la pugna entre el poder militar y político con el poder económico, tal como lo esbozan los siguientes esquemas.

\section{Situación $I$}

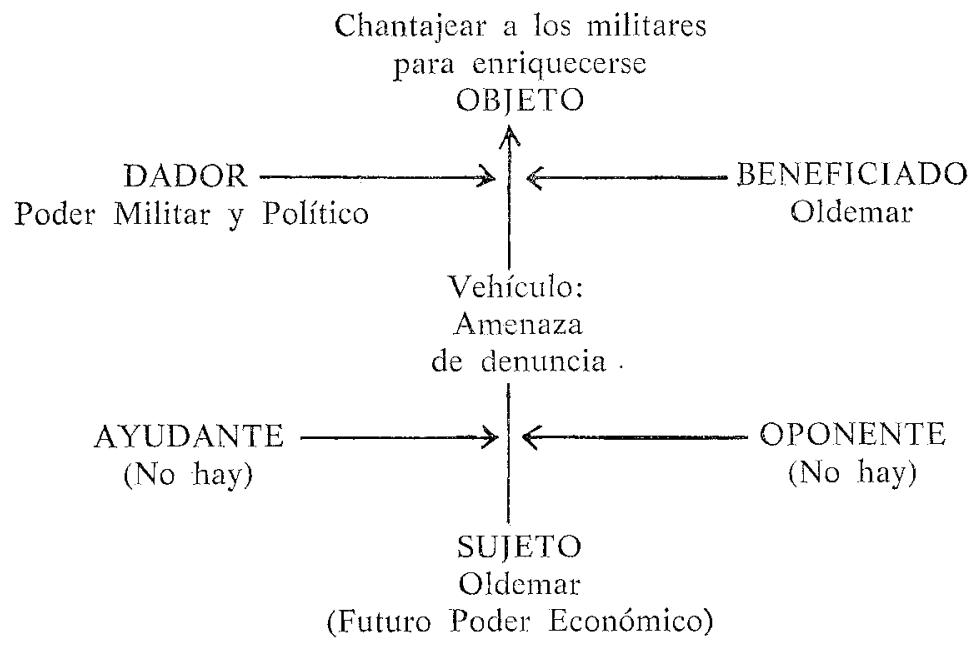

Situación II

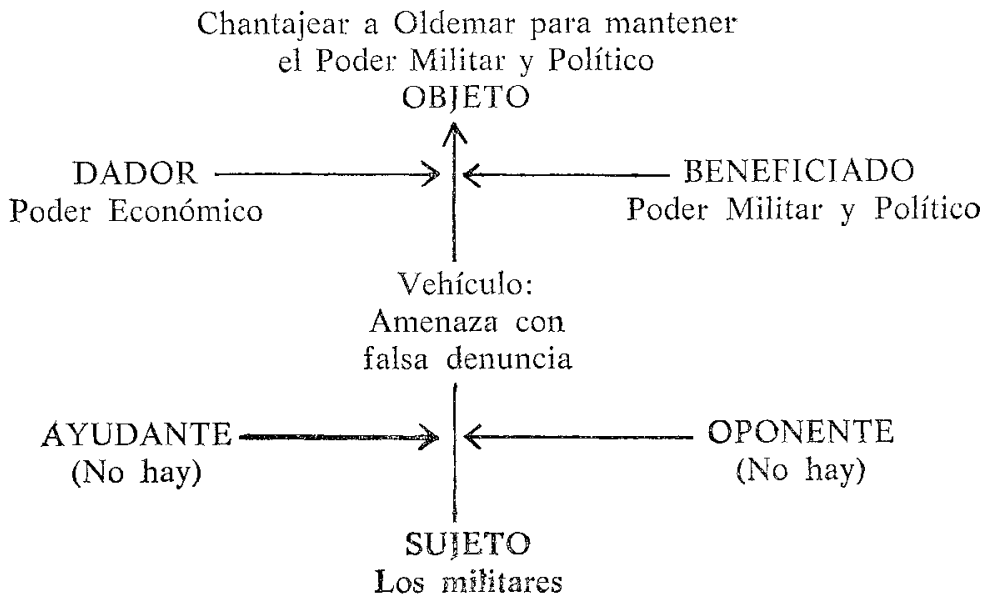


La ausencia de ayudantes y de oponentes evidencia el carácter clandestino de las operaciones. El poder económico prevalece sólo en cuanto virtualidad, pues desde que Oldemar alcanza su objetivo se impone el poder militar y político. Los coroneles advierten a su enemigo que cuando éste era un pobre desharrapado, las gentes podían prestarle oído; pero a un potentado súbito no; la riqueza misma puede ser objeto de sospecha. En ese juego de predominio y servidumbre se denuncian los vicios de los respectivos poderes.

Uvieta, escrita y estrenada en 1980 (en tres actos). ¿Adaptación del cuento del mismo nombre de Carmen Lyra? Más bien se trata de un tema universal: una manera de cómo el hombre enfrenta la muerte, en que Cañas inserta algunas alusiones al referido cuento.

Muy corrientemente la muerte suscita temor. El intento de evadirla o de disminuir su acción tiene ya un largo recorrido en la literatura, lo cual depende de la época y de la cultura a que se pertenezca. Por ejemplo, llama la atención que el teatro clásico griego omita poner la muerte en escena; ocurre fuera de ella. Por el contrario, la representación isabelina, con Shakespeare, por ejemplo, sí ofrecía el espectáculo de la muerte a los ojos del espectador. Algunos se burlan de ella y otros muestran qué sería del mundo y del hombre sin la muerte. En este último destino caben algunas piezas dramáticas como $\mathrm{La}$ muerte de vacaciones, de Alberto Casella; en cierto modo, Con el tiempo prestado, de Paul Osborn; El calendario que perdió siete días, de Enrique Suárez de Deza, y Uvieta, del costarricense Alberto Cañas, para citar unos cuantos ejemplos.

Uvieta se conforma con un plano real y otro maravilloso; éste constituye el soporte de los desenlaces del primero. Dos núcleos de acción -el policíaco y el amoroso- integran el plano real. En efecto, se investiga el crimen contra los esposos Sanabria y el atentado contra Chepe Mico: desde la conjetura hasta la investigación propiamente dicha, aunque ayuna de profesionalismo. Al final, el caso queda sin esclarecer, porque el detective no creyó en la declaración de Noé, en que se responsabiliza del crimen contra Juan Ramón Sanabria.

José LuIs: Hay algunos que, sólo para que la gente crea que se echaron una mujer al pico, son capaces de exponerse a quince años de cárcel ${ }^{2}$.

Luego cuentan las relaciones amorosas entre Eduardo Carvajal y Rosalinda, y las menos verosímiles para los sanluiseños, entre Noé Redondo —más conocido por Uvieta - y Cristina Sanabria. El primer proceso de

\footnotetext{
${ }^{2}$ Alberto Cañas, Uvieta (San José: Editorial Costa Rica, 1980), acto IlI, p. 203.
} 
seducción es el más conflictivo. Rosalinda, joven esposa del viejo Rosendo, desahuciado ya por los médicos, sabe que él está a punto de morir. Pero, a pesar de los pronósticos clínicos, se mantiene con vida (la muerte no actuaba en esos días), por lo que Rosalinda siente escrúpulos y está por renunciar a su futuro matrimonio con Eduardo. Sin embargo, por orden del ángel, Uvieta la convence para que espere. En cuanto al otro proceso de seducción, apenas viene insinuado. Es de suponer que hubo un momento de posesión y otro de renunciamiento, impuesto también por el ángel, para que Cristina se salvara de la mtierte. ¡Cuánto acierto resulta ser que las criaturas del plano real no tengan conciencia de cómo lo mágico incide en los hechos! Si acaso Chico sospecha algo sobrenatural, pues sólo Uvieta está en el secreto de que la vieja trepada en el árbol de mango es la muerte.

El plano mágico presenta a la muerte inhibida para cumplir con su función y los esfuerzos para restituirle sus obligaciones. Nadie ha vuelto a morir en San Luis desde hace quince días. Por ello tiene que intervenir el ángel (una mujer de nombre Lorena, de apariencia anticuada, poco conocedora de los usos del lenguaje de la tierra y de ciertas costumbres en ésta). Viene a pactar con Uvieta el descenso de la muerte, pues el mundo no puede seguir trastornado. El ángel inicia un proceso de convencimiento para que Noé comprenda los riesgos de la stupresión de la muerte. Le concede la vida de Cristina, pero lo separa de ella; además, Uvieta deberá confesar su crimen y ayudar a Rosalinda y a Jupas. Los procesos de este plano crean la atmósfera mágica y proporcionan validez a los del plano real.

Un fuera de escena permite cerciorarse de que se ha generado el proceso de restauración de la normalidad: Pedro Cubero (Jupas) cuenta que venía huyendo de las Oropéndolas (alias de unos hampones), pero que al pasar frente a la casa de Uvieta tropezó con una viejilla (la muerte), y poco después, desaparecieron ésta y los perseguidores. Los hechos ocurren con intervalos de quince días entre acto y acto y siempre en día domingo. Requieren el mismo espacio: el bar-soda de Chico Artavia; en la población de San Luis. Las peripecias, por sí mismas, son regocijantes. El lenguaje, habilísimo, introduce matices de la oralidad, del ingenio, ingenuo y apicarado a un tiempo, de Lorena, del halo de misterio que nimba a Noé y de la intención satírica de Chico y Lorena.

El acontecer muestra la evolución del hombre ante la muerte:

- Deseo particular de conservar a los seres queridos (Uvieta quiere salvar la vida de Cristina).

- Salto de la esfera individual a la social (Uvieta espera que todos vivan felices). 
- Paso al orden cósmico universal (Lorena señala que la muerte es parte de la vida; que ésta se halla diseñada de modo que acabe; que toda la organización de la humanidad y del universo está basada en la muerte. Uvieta, con burlas y con veras, remoza el mito de Eros y Tánatos.

la segua, comedia en tres actos, con prólogo y estrambote (cuasi epílogo), fue estrenada en 1971 y publicada en 1974.

En la tradición popular, la segua corresponde a la leyenda con que nuestros abuelos asustaban a sus hijos trasnochadores. Es bueno notar que cualquier tema en manos de Cañas, aun cuando venga de otros predios, se vuelve muy suyo por las nuevas situaciones en que lo ubica.

El engranaje de esta pieza se mueve en tres esferas: social, factual y maravillosa. La primera de ellas proporciona el espacio. Tiene carácter presentativo, pues reúne los elementos indispensables para escenificar el Cartago colonial de mediados del siglo xvirr. Allí se dan cita diversas clases sociales: señores descendientes de españoles radicados en Cartago (familia de Encarnación Sancho y otras); españoles recién venidos, segundones de espíritu aventurero (Camilo); sacerdotes (fray Diego); criados (Manuela), indios, pardos; prostitutas y brujas (María Francisca y Petronila). Revela un país agrícola cuya población no tiene grandes ambiciones; ambiente pacífico sin más perturbaciones que las provocadas por las interferencias de los piratas, como lo explica José Manuel Sancho. Las familias son de costumbres sencillas, celosas de su honra; en ellas prevalece la autoridad paterna, aun para darles estado a los hijos; así podía sobreponerse el interés al efecto entre los contrayentes y producir uniones de mujeres jóvenes con pretendientes ancianos, pero ricos, como sucede entre Encarnación y don Félix. La religiosidad, mezclada con creencias supersticiosas, está también a la orden del día, lo mismo que la murmuración. La esfera amorosa adquiere valor factual. Los diversos enamoramientos hacen avanzar la acción.

Encarnación Sancho, la más bella niña de Cartago, tras su frustrado amor con el teniente Corona (loco a causa de un mal venéreo incurable), se cree embrujada por las malas artes de María Francisca y de Petronila: involuntariamente se convierte en segua y hace enloquecer a sus pretendientes. Esta perturbación de la joven coloca las bases del clima maravilloso. $Y$ aunque, individualmente, todos saben que no hay tal brujería, nadie se atreve a contrariar el talante de la protagonista, quizá porque. los patrones culturales a que obedecen no rechazan del todo las supersticiones.

Así, la esfera maravillosa, conjunto de las facetas mágicas, tiene fuerza determinativa, porque de ella depende la conducta de los personajes, al mismo tiempo que engloba a las otras dos esferas. 
Manuela: $\quad$... Converse con mis amos y propóngales una bendición; ellos lo aceptarán... y quizás así recobre la razón mi niña. ¿No lo cree?

Fray Diego: Lo dudo, porque es trastorno mental y no encantamiento como tú dices. (Pausa.) Pero, viéndolo bien, podría intentarse ${ }^{3}$.

Tal perspectiva de mundo produce en la esfera factual (la amorosa) un juego de acercamientos y alejamientos.

\section{ACERCAMIENTOS}

\section{ALEJAMIENTOS}

\section{Relaciones Camilo-Encarnación}

- José Manuel acepta que Camilo visite a su hija.

- José Manuel se lleva a Camilo tras su primera visita, porque aquél va a salir.

- Con la buena tercería de Manuela se produce en la calle el primer encuentro a solas de los jóvenes, donde Camilo le declara su amor a gritos.

- Camilo quiere que Encarnación le prometa esperar su regreso de Tisingal. Ella no acepta porque teme que él sea embrujado en ese lugar.

- Camilo parte a la expedición seguido poco después por Petronila (mala tercería de María Francisca).

- José M. rechaza a Camilo como pretendiente de su hija por mujeriego y amigo de pendencias.

- Nuevo encuentro en la calle con la ayuda de Manuela, para una posible reconciliación entre Encarnación y Camilo.

${ }^{3}$ Alberto Cañas, La segua y otras piezas (San José: EDUCA, 1974), acto II, p. 41 . 
- Encarnación lo rechaza, aunque lo ama, porque están embrujados: ella no quiere ser segua, ni que el amado la vea envejecer.

- Camilo, en compañía de Zenón, busca una vez más a la joven, cuando ella ya está casada con don Félix.

- Encarnación parte a Guatemala en compañía de su marido, mientras Camilo muere apuñalado por Petronila. La gente cree que fue un suicidio por amor.

\section{Relaciones Encarnación-Don Félix}

- Cuando don Félix aún no era ciego y Encarnación una niña pequeña, había asiduidad entre ambos. (Fuera de escena.)

- Don Félix se va a radicar a Guatemala. (Fuera de escena.)

- Don Félix ha regresado, viejo, ciego y rico; se ofrece como padrino de boda de Encarnación.

- Don Félix pide la mano de Encarnación. (Fuera de escena.)

- Encarnación demora su respuesta.

- Encarnación decide casarse con don Félix, como, en efecto, ocurre.

E1 amor con Corona — situación inicial — ya estaba fracasado cuando se levanta el telón, pero deja condicionada a la muchacha, que desde entonces padece un gran desequilibrio anímico: a) se cree embrujada; b) está persuadida de que ella es la segua; c) ser segua consiste, además, en reunir en sí todo lo desagradable, como envejecer, agriar el carácter, perder su atractivo; d) su mal degenera en narcisismo: ama su propia. belleza sobre cualquier otra cosa. 
Con Camilo adopta una actitud inhibitoria, porque no quiere que éste la vea envejecer y convertirse en segua. La unión con don Félix responde al mismo estado psíquico: como él es ciego, no verá marchitarse su fragancia juvenil. Por otra parte, económicamente es un buen partido, aspecto en que fue sutilmente manipulada por José Manuel. La boda con don Félix fue, pues, un matrimonio por conveniencia psíquica y económica.

Puede corroborarse ahora cómo el eje significativo oscila entre LO MARAVILloso y LO NO MARAVILloso. Lo mágico, con su desborde hacia lo psicológico (el narcisismo de la protagonista) y hacia lo trascendente (ella no quiere envejecer, otro modo de ser segua), constituye un intento de subvertir el orden natural para derribar la cárcel del tiempo.

El universo de La segua está presentado desde el punto de vista de Encarnación, en lo psicológico; y según la óptica de la clase alta, en lo social. Sin embargo, los comentarios de la gente, señores o no, parecen enjuiciar ese cuadro. Por eso, conforme los murmuradores se alejan de los hechos, los van deformando, hasta llegar a los estudiantes de 1971, para quienes las intimidades de una familia carecen de importancia frente a los angustiosos y serios problemas del mundo.

Este breve recorrido sobre temas y procedimientos teatrales en torno a los más significativos autores apunta a la dosis de madurez alcanzada por nuestra dramaturgia, incrementada por la proliferación de grupos de artistas profesionales y de salas de espectáculo. El público tiene siempre varias opciones en las carteleras para acomodarse según sus preferencias. 